\title{
Quiet Kindness in School: Socially and Emotionally Sophisticated Kindness Flying Beneath the Radar of Parents and Educators
}

\author{
John-Tyler Binfet \& Camilla Enns
}

\begin{abstract}
John-Tyler Binfet is a kindness researcher at the University of British Columbia. An associate professor in the Okanagan School of Education, his research examines how kindness is understood and facilitated within the context of public schools. He is the lead author of the School Kindness Scale and his previous work on kindness has been published in the Canadian Journal of School Psychology, Psychology in Schools, the International Journal of Emotional Education, and the Canadian Journal of Childhood Studies. Email: johntyler.binfet@ubc.ca
\end{abstract}

Camilla Enns recently completed her BA at the University of British Columbia with a double major in psychology and geography.

This paper profiles the different ways in which elementary and middle school students report on their acts of kindness and introduces the concept of quiet kindness, a socially and emotionally sophisticated form of kindness that does not draw attention to the initiator, where the recipient remains potentially unaware of the act, and the kind act is not likely acknowledged or reinforced by external agents. Examples from surveys of over 3,000 Canadian elementary and middle school students help illustrate how children enact kindness in school. The developmental implications of quiet kindness for children are discussed alongside implications for parents and educators.

Keywords: kindness; children; prosocial behaviour; educators; parents
A search of the extant psychological and educational literature on the topic of kindness reveals three distinct trends: (1) the majority of studies on kindness have involved adult participants (e.g., Aknin, Sandstrom, Dunn, \& Norton, 2011; Chancellor, Margolis, JacobsBao, \& Lyubomirsky, 2017; Trew \& Alden, 2015); (2) the bulk of intervention research has assessed the pre-topost effects of having participants engage in kind acts to identify possible benefits to well-being (e.g., Curry et al., 2018; Dunn, Aknin, \& Norton, 2014; Layous et al., 2012; Layous, Nelson, Kurtz, \& Lyubomirsky, 2017; O'Connell, O’Shea, \& Gallagher, 2015; Otake et al., 2006; Rowland \& Curry, 2018); and (3) there is emerging work exploring how, when asked to be kind, individuals enact kindness (e.g., Binfet \& Passmore, 2017; Cotney \& Banerjee, 2017).

Complementing kindness intervention research is research identifying how children and adolescents demonstrate kindness, particularly within the school context. Understanding how students demonstrate kindness is important because it informs the adult agents responsible for fostering and guiding the development of children's prosocial behaviour, providing insights into how children understand and express kindness as part of their repertoire of school-based behaviours.

The aim of this paper is twofold: First, to draw attention to the different ways in which students demonstrate kindness and, in particular, to illustrate quiet examples of students' kindness-kind acts that do not draw attention to the initiator and in which the initiator is anonymous, where recipients remain potentially unaware of the act, and acts that are not likely acknowledged by external agents whose role within the school might be to reinforce students' prosocial behaviour; and second, to explore the developmental implications of quiet kind acts given their relative social and emotional sophistication vis-à-vis other, more commonly performed acts of kindness. Using examples from surveys of over 3,000 Canadian elementary and middle school students to illustrate how children enact kindness, it is our intention to increase the awareness of educators and parents around the variety of kind acts taking place within school communities. 


\section{Defining kindness}

Recent work by Lee Rowland (2018) has initiated discussion about "what is kindness?" and disentangles our understanding of kindness vis-à-vis altruism and compassion. "The essence of kindness," Rowland suggests, "is more nuanced than we often consider. It is not a single thing, does not perfectly overlap with altruism and compassion, and has both behavioural and affective components" (p. 33). Distinct kindness definitions are not readily reported in the literature (for a recent summary of published definitions, see Binfet, 2015). Certainly, the bulk of definitions of kindness reflect broad definitions (i.e., kindness outside of the school context) and comprise adult interpretations of kindness (i.e., not kindness as understood by children themselves). Within the context of this article, kindness is defined as follows: "Kindness, from the perspective of young children, is an act of emotional or physical support that helps build or maintain relationships with others" (Binfet, 2015, pp. 36-37). Given that most schools' mission or vision statements embrace some aspect of this definition combined with the collective educational importance we place on students' prosocial interactions in school, it may help educators and parents to understand the different ways in which kindness is expressed by students.

\section{Kindness research}

\section{Intervention studies}

It is not surprising that the majority of studies of kindness to date consist largely of interventions in which participants are asked to complete kind acts; across studies, doing so has proven effective in augmenting participants' wellbeing (Rowland \& Curry, 2018; Post, 2017). With few exceptions these studies have sampled adult participants (e.g., Kerr, O'Donovan, \& Pepping, 2014; Otake et al., 2006) and there is a distinct lack of research on the effects of being kind in children. In one of the few studies in which children were asked to perform kind acts, Layous and colleagues (2012) had 9- to 11-year-olds perform three kind acts each week for four weeks in an effort to boost their well-being. Pre-to-post assessments of well-being indicated significant boosts for students who participated in the kindness intervention and significant increases in their social acceptance by peers.

\section{Conceptualizations of kindness studies}

The focus of the empirical work above on kindness has come, perhaps, at the expense of understanding how participants conceptualize kindness, that is, how kindness is understood and manifested by participants. The emerging work in this area is limited and includes burgeoning work by researchers in Canada (Binfet, 2016; Binfet \& Gaertner, 2015; Binfet \& Passmore, 2017) and the UK (e.g., Cotney \& Banerjee, 2017) who have asked children and adolescents to describe the kind acts they either generated or received. It warrants mentioning that when children are asked to provide examples of kindness they have done, especially acts done within a school context, children might be reporting kind acts arising from explicit instruction as part of the social and emotional curriculum taught in schools.

Across participants and across studies, commonalities in the themes of kind acts done by children have been found (Binfet, 2016). Young children have been found to enact kindness through physically (e.g., "I helped someone get up who fell") and emotionally (e.g., "I played with a new girl who was lonely") helping others. Young students also were found to show kindness by sharing (e.g., "I gave him half of my snack") and including others (e.g., "My friends and I were playing and he was alone so we said 'Hey come join us!"”).

The repertoire of kind acts done by older children and adolescents is broader and includes themes such as showing respect ("I could have budged in line but I waited"), advocating for others (e.g., "I stood up for him when he was bullied"), and complimenting others (e.g., "I told him I liked his skateboard"). Findings in recent research on 
kindness in adolescents by Jessica Cotney and Robin Banerjee (2017) identified 10 thematic categories of kind acts: emotional support, helping, generosity, positive sociality, honesty, forgiveness, complimenting, proactive support, formal kindness, and social inclusion.

\section{Variations in children's kind acts}

Those of us who research kindness and practitioners who encourage kindness in children recognize there are different approaches to encouraging and enacting kindness within school contexts. Though not much has been written on differentiating the approaches to fostering kindness, it warrants discussion, certainly as parents and educators seek ways to support young people in their academic, social, and emotional development. Further, as children's developmental needs vary, so too does the level of support or structure they require surrounding how to be kind. What follows next is an overview of the principal ways through which children might be encouraged to be kind and the different pathways through which they might express kindness.

\section{Random acts of kindness}

The origins of the phrase "random acts of kindness" lie in Anne Herbert's 1982 placemat slogan "Practice random kindness and senseless acts of beauty" and subsequent coauthored book of the same title (Herbert \& Pavel, 1993). Certainly this phrasing has garnered much lay attention, with online organizations arising in response to the public's interest in fostering spontaneously performed kindness. A random act of kindness might be considered an emotional, social, or physical response that offers support to someone in their immediate moment of need (e.g., a student drops their books in the hallway and a passing fellow student stops to help gather them). Random acts of kindness are certainly evident in schools. The examples below illustrate early (grades K-3) and older (grades 4-5) students' demonstrations of kindness in response to the needs of others.

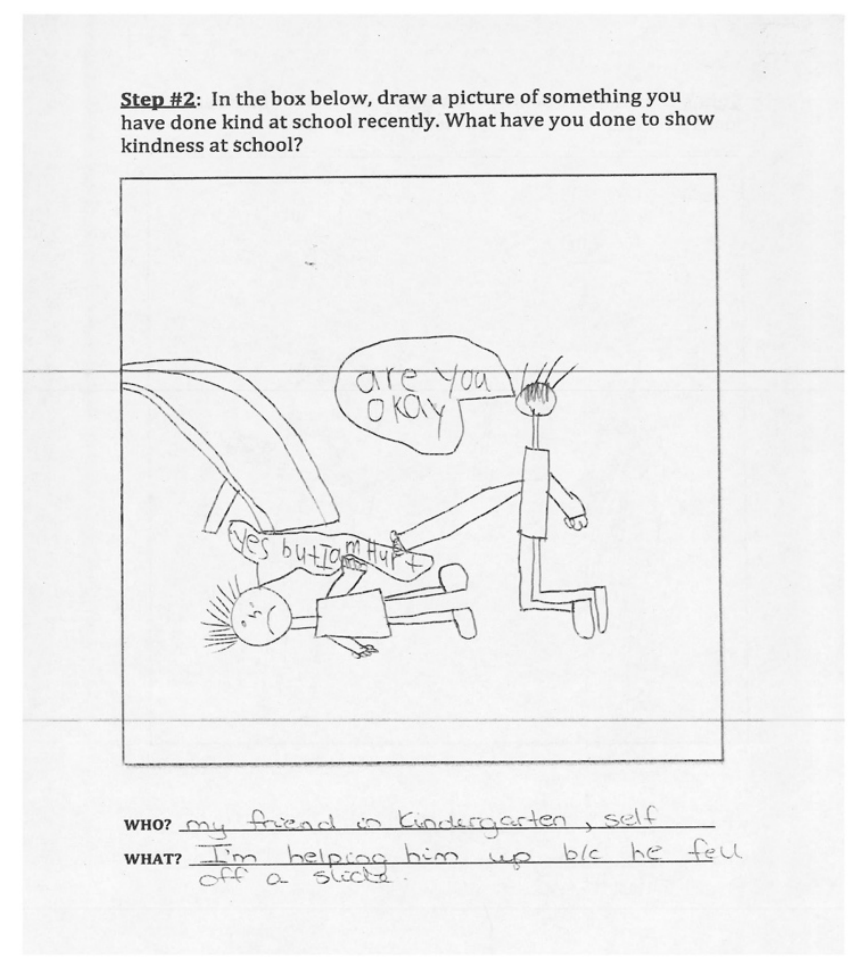

Figure 1. Random act of kindness, early elementary example. 


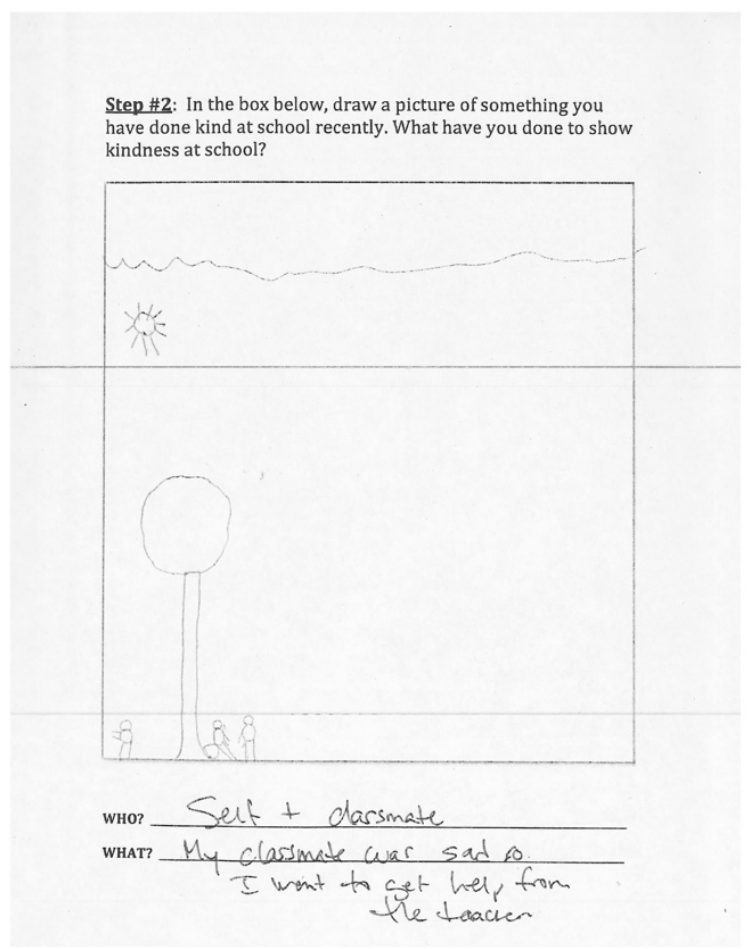

Figure 2. Random act of kindness, early elementary example.

3. What is an example of kindness YOU have done at school? (Describe) I've held the dooropen if someone was carrying a heary object. Littlethings makea difference.

Figure 3. Random act of kindness, intermediate example.

3. What is an example of kindness YOU have done at school? (Describe) I have seen peopte lonely, and invited them to have fun with me and my trients. That is an example of kindness. I have done axthis shool

Figure 4. Random act of kindness, intermediate example.

3. What is an example of kindness YOU have done at school? (Describe)

I broight someone to the office when they
hurt their ankle.

Figure 5. Random act of kindness, intermediate example. 


\section{Intentional acts of kindness}

In contrast to random acts of kindness in which kindness is perhaps more reactionary (i.e., in response to a perceived need), the notion of a more structured approach to being kind has been proferred (Binfet, 2015). Being intentionally kind involves planning, gathering resources, identifying recipients, scheduling, and execution-all factors that, combined, do not typically characterize being randomly kind. Researchers (e.g., Layous et al., 2012) have employed a structured or intentional approach to having participants perform kindness (e.g., "Plan and perform three kind acts over the course of the next week"). When asked to plan kind acts (i.e., to be intentionally kind), children manifest kindness in a variety of ways, and this emerging area of kindness research, whereby participants are asked to be intentionally kind, is gaining ground in both psychological and educational literature (Rowland \& Curry, 2018).

Below are illustrations of how children typically demonstrate intentional kindness in school. These examples are shared to allow a comparison to what we postulate is a more sophisticated version of kindness-quiet acts of kindness. Across each of these examples of intentional kindness, the initiator is known to the recipient, the delivery of the act involves some sort of interaction between the initiator and the recipient, and there is a certain a priori planning that precedes the kind act.

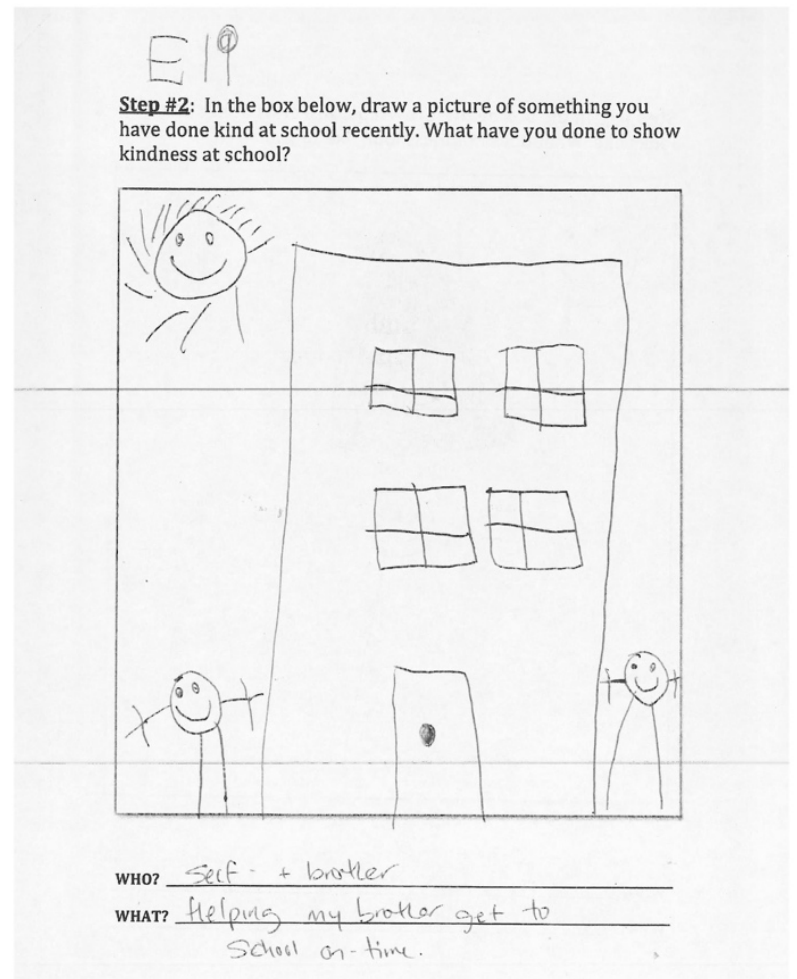

Figure 6. Intentional kindness, early elementary example. 


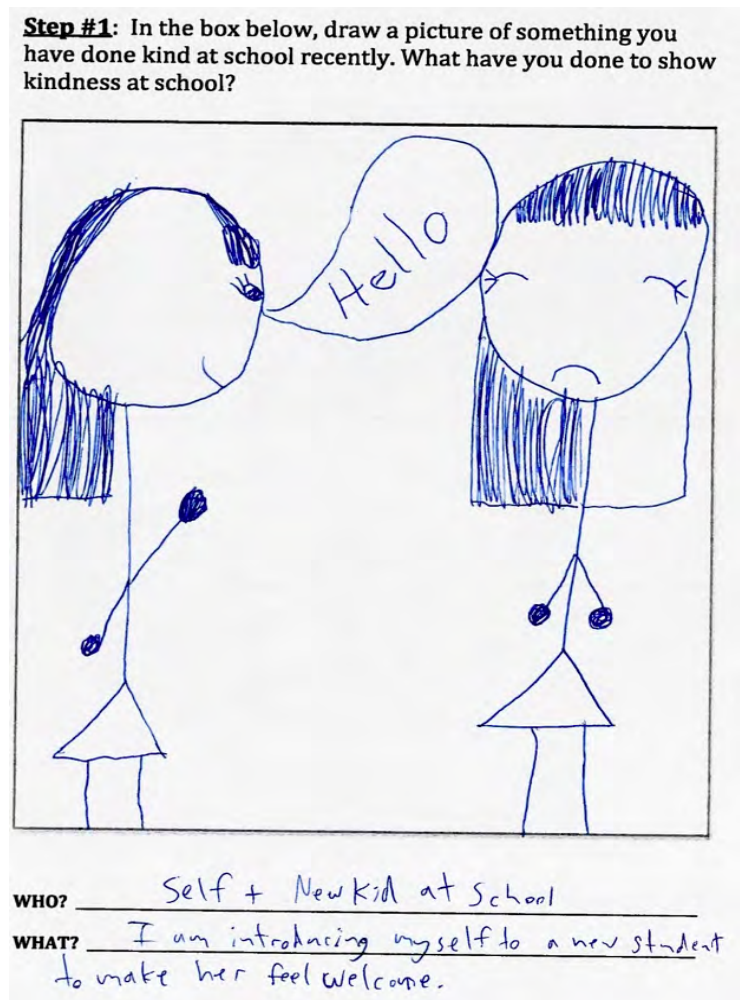

Figure 7. Intentional kindness, early elementary example.

3. What is an example of kindness YOU have done at school? (Describe)

We have a special needs garl at orr school and I don't know hor but she thinks I'm her best friend and I play along and pretend
Im her best friend

Figure 8. Intentional kindness, intermediate example.

3. What is an example of kindness YOU have done at school? (Describe)

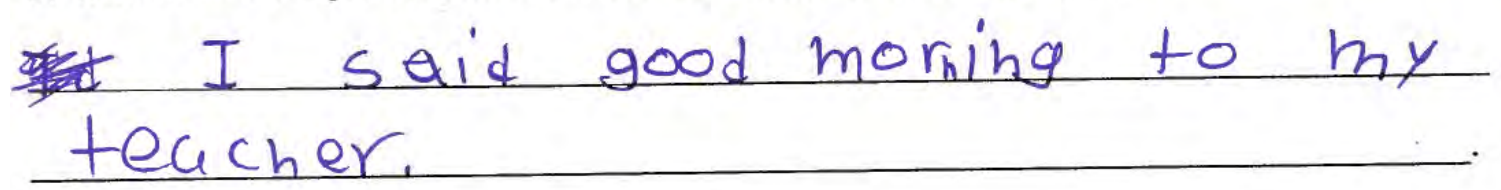

Figure 9. Intentional kindness, intermediate example. 


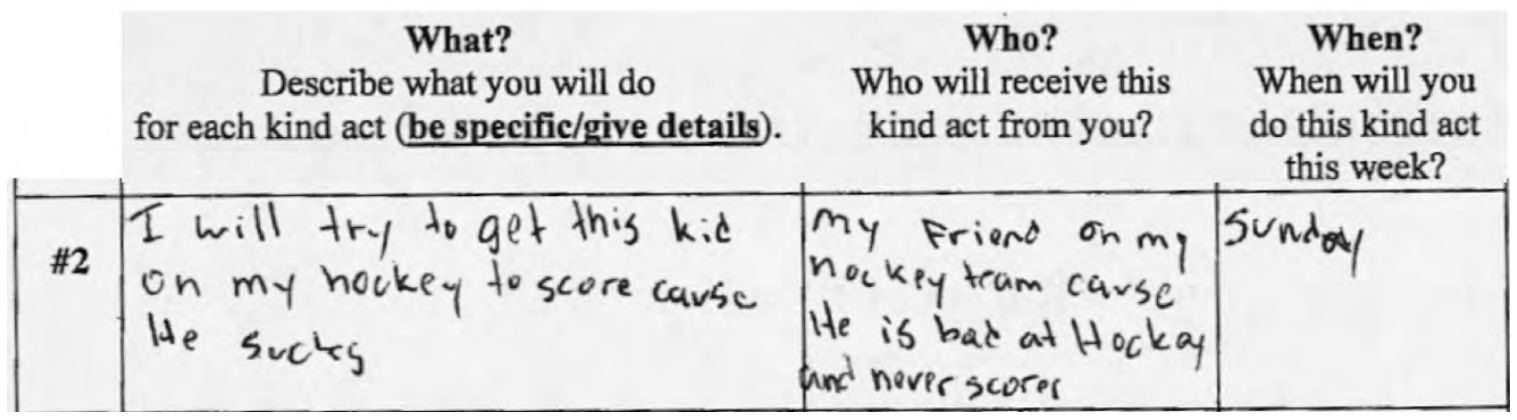

Figure 10. Intentional kindness, middle school example.

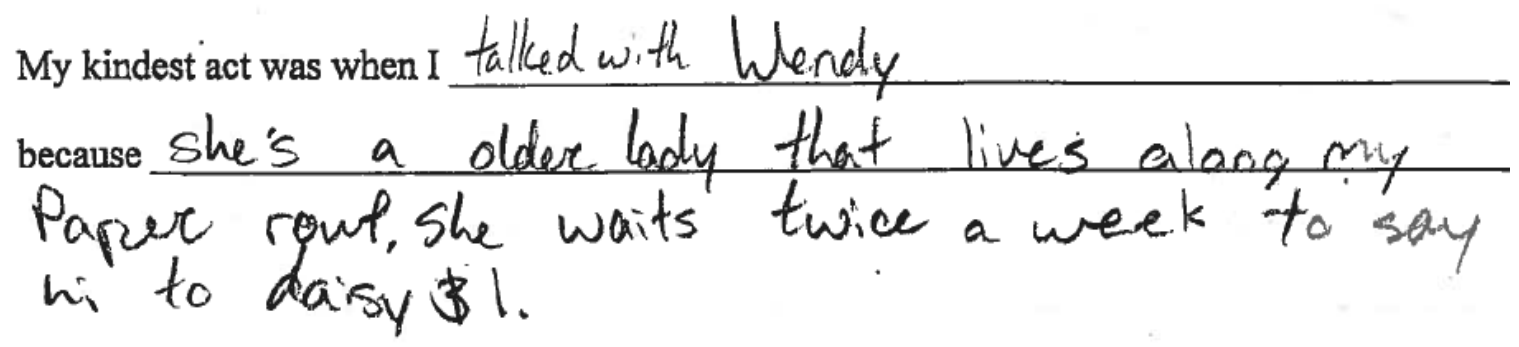

Figure 11. Intentional kindness, middle school example.

\section{Quiet acts of kindness}

As mentioned, the first author has undertaken several studies to understand how kindness is conceptualized in school, querying, to date, over 3,000 public school students about how they are kind. These studies include asking kindergarten to third graders to draw acts of kindness they have done in school (Binfet \& Gaertner, 2015). Older students in grades 4 through 9 have been asked outright to describe kind acts they have done in school (Binfet \& Passmore, 2017). Across participants, much has been learned about how young people understand and demonstrate kindness. Though the key themes of children's kindness have already been reported, what emerges from this body of research is a subset of kind acts, termed here "quiet kindness," that stand apart from the kindness typically performed by school children. As introduced at the outset of this paper, quiet kindness comprises kind acts that do not draw attention to the initiator (i.e., the student initiating this kind act is likely unmotivated by seeking recognition for being kind), the kind act is not announced to the recipient, an individual who may very well remain unaware of the kind act performed on their behalf, and the kind act does not garner the attention of any adult agents who might typically encourage or reinforce kindness within the school context. Quiet kind acts contrast what Gustavo Carlo and Brandy Randall (2002) termed "public prosocial behaviors" which are conducted in front of an audience to gain approval. What follows are six illustrations of children's quiet kind acts. It is our hope in sharing these examples of quiet kindness that parents and educators and, in turn, students themselves, can see the nuanced and complex ways in which kindness might take shape within a school. 


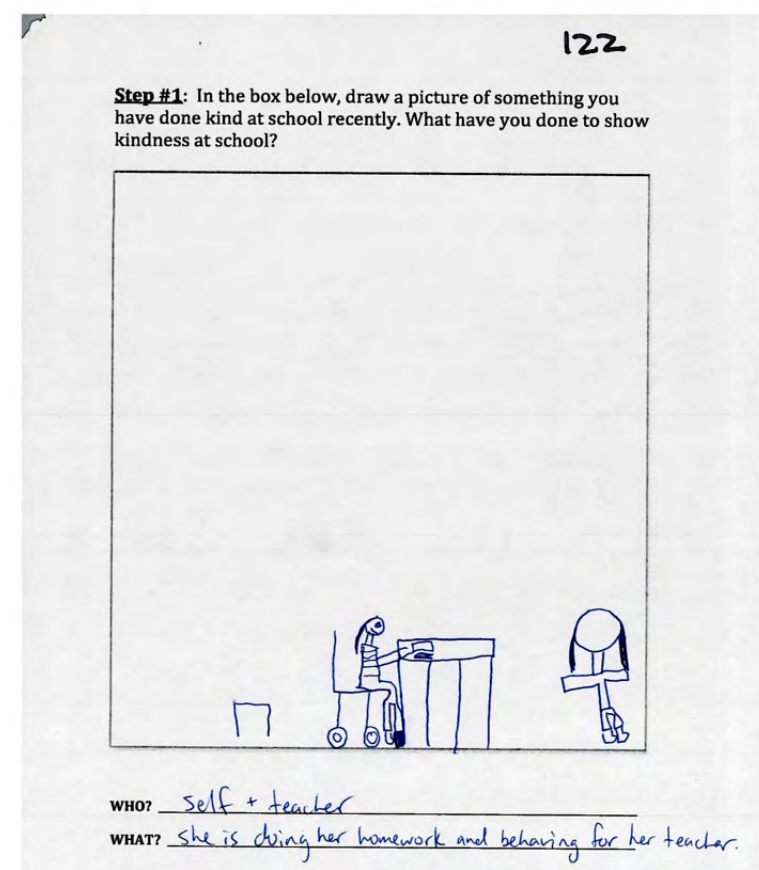

Figure 12. Quiet kindness, early elementary example.

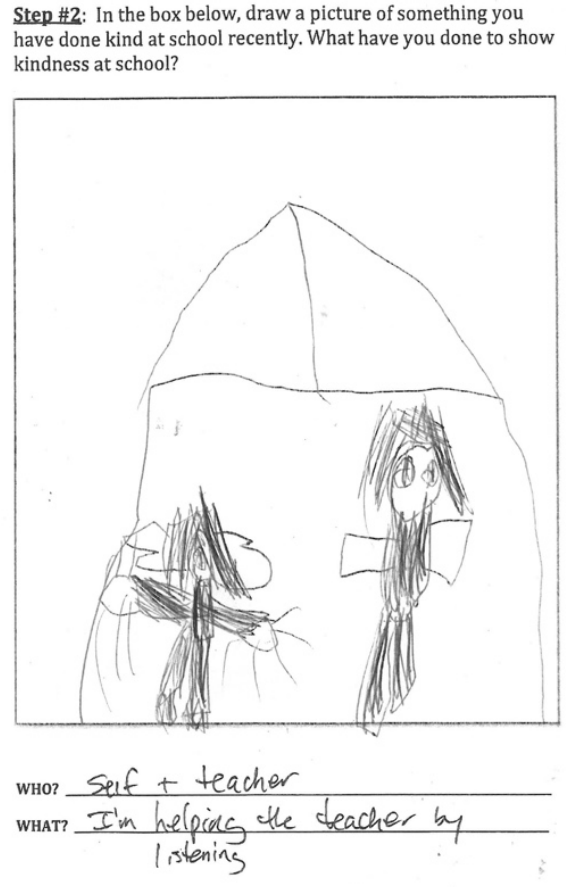

Figure 13. Quiet kindness, early elementary example. 


\begin{tabular}{|c|c|c|}
\hline $\begin{array}{l}\text { Describe each kind act below (be } \\
\text { detailed!). }\end{array}$ & $\begin{array}{l}\text { Describe who this kind act } \\
\text { is for and how you know } \\
\text { this person (e.g., classmate, } \\
\text { friend, teacher, stranger) }\end{array}$ & $\begin{array}{l}\text { Do you know } \\
\text { this person or } \\
\text { group? Circle } \\
\text { one. }\end{array}$ \\
\hline $\begin{array}{l}\text { Aet 2: Take the } \\
\text { straws ont of suice } \\
\text { boxes before you } \\
\text { secycle them } \\
\text { (at school) }\end{array}$ & $\begin{array}{l}\text { For: School } \\
\text { Greenteam }\end{array}$ & No \\
\hline
\end{tabular}

Figure 14. Quiet kindness, middle school example.

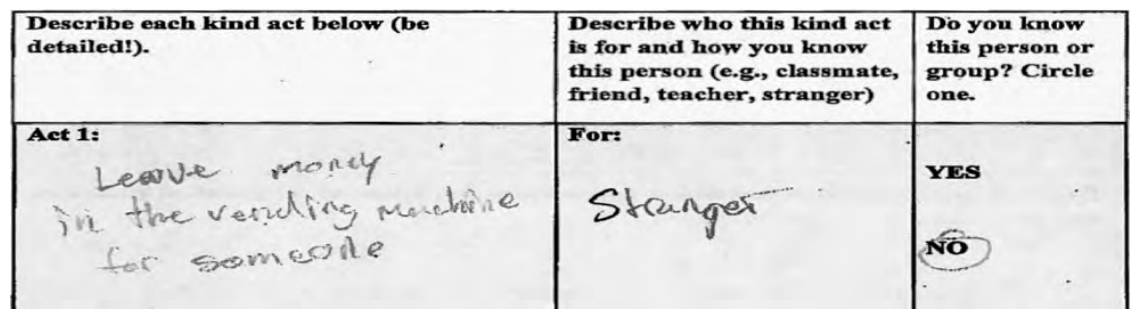

Figure 15. Quiet kindness, middle school example.

\begin{tabular}{|c|c|}
\hline $\begin{array}{l}\text { Describe each kind act below (be } \\
\text { detailed!). }\end{array}$ & $\begin{array}{l}\text { Describe who this kind act } \\
\text { is for and how you know } \\
\text { this person (e.g., classmate, } \\
\text { friend, teacher, stranger) }\end{array}$ \\
\hline $\begin{array}{l}\text { Act 2: Be more corfal of } \\
\text { mentioning things aboat } \\
\text { my mom in fiont of } \\
\text { Cole because his died } \\
\text { of cancer last kcar }\end{array}$ & $\begin{array}{l}\text { For: Lole he is } \\
\text { my class mote and } \\
\text { fliend. }\end{array}$ \\
\hline
\end{tabular}

Figure 16. Quiet kindness, middle school example.

\begin{tabular}{|l|l|l|}
\hline $\begin{array}{l}\text { Describe each kind act below (be } \\
\text { detailed!). }\end{array}$ & $\begin{array}{l}\text { Describe who this kind act } \\
\text { is for and how you know } \\
\text { this person (e.g., classmate, } \\
\text { friend, teacher, stranger) }\end{array}$ & $\begin{array}{l}\text { Do you know } \\
\text { this person or } \\
\text { group? Circle } \\
\text { one. }\end{array}$ \\
\hline Act 3: For give people fe & For: sister & \\
\hline
\end{tabular}

Figure 17. Quiet kindness, middle school example. 


\section{Quiet acts of kindness reflect social and emotional sophistication}

The study of kindness in children falls neatly within the framework of the broader field of social and emotional learning (SEL), a field of study whose aim is to illuminate the intrapersonal, interpersonal, and cognitive competencies children learn across varied settings (Collaborative for Academic and Social and Emotional Learning, 2015). Such competencies include self-awareness, self-management, social awareness, relationship skills, and responsible decision making (see https://casel.org/ for a detailed description of each competency). Although it can be argued that performing any act of kindness requires or draws on these core SEL competencies, might quiet acts of kindness illustrate a more sophisticated mastery of these competencies? As the above examples of quiet kindness illustrate, children who demonstrate this type of kindness appear to embrace, to a greater extent, the pillars of SEL. This might be evident in children's perspective-taking abilities and ability to recognize the need for kindness to be directed to others (i.e., self- and social awareness), the ability to gather resources and plan acts of kindness (i.e., self-management and responsible decision making), and the social skills needed to deliver kind acts to others (i.e., relationship skills).

It merits noting that each of the over 3,000 participants in the above-referenced studies generated between two and 12 acts of kindness. Given the volume of this data, a calculation of the frequency of kind acts by the new kindness categories described in this paper has yet to be determined. The coding of children's kind acts by the three kindness categories discussed here is currently underway.

\section{The role of reinforcement in shaping children's behaviour}

Children develop in complex social and emotional environments and thus may act prosocially for a variety of reasons. In a review of the motivations behind prosocial behaviour, Maayan Davidov and colleagues (2016) describe the socialization processes that take place throughout childhood development. Although infants appear to show altruistic kindness (e.g., helping to reach an object) within their first year, positive experiences associated with kind behaviour help to reinforce continued kind behaviour among children. Positive experiences include receiving praise or a reward, having a pleasant interaction with a trusted adult, feeling a positive emotional state, and the satisfaction of adhering to social norms (Davidov, Vaish, Knafo-Noam, \& Hastings, 2016). However, children receive widely varying levels of reinforcement depending on their social environment (Bower \& Casas, 2016). It is argued that reinforcement by respected adults in children's lives has an influence on children's prosocial behaviour (Dahl et al., 2017; Grusec, Goodnow, \& Kuczynski, 2000; Hastings, Utendale, \& Sullivan, 2007; Taylor \& Biglan, 1998).

Within both family and school contexts, interventions designed to increase kind behaviour in children typically use reinforcement as a cornerstone strategy (Biglan, Flay, Embry, \& Sandler, 2012). A common example is giving children a weekly allowance for helping around the house (Warton \& Goodnow, 1995). Dahl (2015) argues that encouragement and reinforcement from parents shapes children's prosocial behaviour by providing knowledge, allowing children to practice social skills, and promoting habits. Although parents are thought of as the most influential factor in children's development (Parke \& Buriel, 2006), educators also play an important role in shaping children's behaviour (Jennings \& Greenberg, 2009). Readers curious to understand the nuanced nature of how children perceive kindness in school and, in particular, in teachers, are directed to a recent publication by Binfet (2016).

Because students come from diverse family contexts, with some students being undersocialized at home and arriving to school lacking the requisite social and emotional skills needed to thrive (Ashdown \& Bernard, 2012; Rimm-Kaufman, Pianta, \& Cox, 2000), educators increasingly find themselves teaching children skills historically 
taught at home (Jennings \& Greenberg, 2009). In a long-term study, Sheppard Kellam and colleagues (2008) identified that teachers could increase the prosocial behaviour of first and second graders using a team-based game in which students received rewards for displaying prosocial behaviour, with effects lasting until age 21. Further, Asha Spivak and Dale Farran (2012) studied 124 first-grade classrooms to see which teacher behaviours were most associated with student kindness. These researchers found verbal encouragement of prosocial and empathetic behaviour strongly associated, whereas emotional warmth, positive behaviour management, and instruction on their own were not influential in shaping children's behaviour. They concluded that deliberate reinforcement from educators holds power to encourage kindness in children. However, it should be noted that results of these studies are typically correlational. Reinforcement can be difficult to measure in isolation as it occurs in dynamic and multifaceted social situations.

Not everyone is in agreement with the use of reinforcement to shape children's behaviour, with some researchers arguing that using material rewards can harm the natural motivation to do good (Biglan, 2003; Dahl, 2015). This certainly is evidenced by research by Felix Warneken and Michael Tomasello (2014), who assessed three reinforcement conditions (social praise, material reinforcement, or no reinforcement) in promoting prosocial behaviour among toddlers. Their research illustrated that the use of material rewards did not encourage subsequent prosocial behaviour in this age group. Despite these cautions regarding the use of reinforcements, Audun Dahl (2015) acknowledges that reinforcement may play a key role when motivation is especially low.

Reinforcement can take many different forms. Alicia Bower and Juan Casas (2016) asked parents of young children how they respond upon witnessing their children engaging in various kind acts. The parents' answers ranged from giving their child a wink to a statement such as "That was very nice of you to sit with that child when they were hurt. You were very kind." Parents were most likely to give general praise (62\%), defined as praising the act only, as opposed to praising the child's character, giving physical affection, communicating their approval, or giving physical gifts or treats. Nevertheless, not all reinforcement is equally effective. Jennifer Henderlong and Mark Lepper (2002) explain that giving praise is beneficial to a child when it does not convey the message that the child has low ability, when self-efficacy is acknowledged, when it does not involve social comparison, and when expectations are realistic. Researchers also agree that certain types of reinforcement vary in effectiveness based on the age of the child, as kindness becomes more complex with maturity. For example, reinforcement is most successful for young children when they are asked to perform something more difficult than they would naturally (Dahl et al., 2017), for 8-year-olds when their character or motivation is acknowledged (Grusec \& Redler, 1980), for adolescents when they expect their parents to respond fairly (Hardy, Carlo, \& Roesch, 2010), and overall when implemented early on and maintained throughout childhood and adolescence (Flannery et al., 2003). Empathy education within reinforcement has also been consistently shown to increase children's prosociality. Encouraging children to think empathetically about the needs and feelings of others increases kind behaviour (Howard \& Barnett, 1981; Kalliopuska \& Tiitinen, 1991).

\section{Discussion}

The examples of quiet kindness shared in this article illustrate how children are kind in ways that others cannot always see. It has been argued here that acts of quiet kindness require the mastery of advanced social and emotional competencies - a relative sophisticated mastery of social awareness, of perspective taking, of self-regulating and self-management, and of responsible decision making. Certainly, children who demonstrate quiet kindness are less inclined to receive praise or reinforcement from the adult agents within their home or learning context whose responsibility it is to encourage prosociality. In this regard, their acts of kindness might be considered less externally driven than other forms of kindness which may generate praise for the kind-doer. Quiet acts of kindness 
may reflect more sophisticated attachments to others, with the acts themselves carrying particular meaning for a relationship between the kind-doer and the recipient.

One aim of this paper has been to sensitize adult agents who hold the power to shape children's behaviour to be aware that children do enact kindness quietly and moreover that adults in varied learning contexts are likely unaware of the extent to which children are, in fact, kind. It might be argued, however, that children who engage in quiet kindness, given their relatively sophisticated social and emotional skills, are less in need of reinforcement.

Our discussion of the different ways kindness can be enacted within a school context draws attention to the inherent biases that might exist in schools to encourage children to be kind in predetermined ways. That is, might our efforts in schools to date have overlooked the variety of ways in which children might express kindness to others by focusing on narrow definitions of kindness evident in prepackaged curricula? This, in turn, impacts how the adult agents in the lives of children discuss, encourage, and reinforce kind behaviour. Related to this, might we be conditioning students to seek reinforcement for being kind within school and family contexts, losing sight of the intrinsic value of kindness itself? Our hope in introducing the concept of quiet kindness is to initiate and broaden the dialogue among parents, educators, and researchers around the possibilities of expressions of kindness that could take place in schools. Certainly, heightened awareness is needed around the variety of kind acts taking place in schools as we seek to shape school cultures that celebrate students' prosocial behaviour.

The identification of quiet acts of kindness generates questions for educators, parents, and researchers striving to understand the role that kindness plays in children's lives. For example, might quiet kindness be, to a greater extent, characteristic of shy or introverted students? Certainly, given the social and interaction demands inherent in performing random and intentional kind acts, quiet kindness allows the initiator to play a relatively unassuming role. Further, the identification of quiet kindness holds implications for parents and educators seeking to reinforce kindness in children. By virtue of their low-profile presence, children's quiet kind acts go largely unacknowledged by the adult agents who typically reinforce such behaviour.

Certainly an area of research warranting further discovery is the link between SEL and kindness. How does social and emotional competence influence children's abilities to enact kindness? Extending further, future research might explore how children's social and emotional competencies impact their demonstrating random, intentional, and quiet kindness. As well, researchers and practitioners collectively might explore the linkages among the different forms of kindness. Might children first be instructed on how to be intentionally kind, then encouraged to enact random acts of kindness, and subsequently be encouraged to perform quiet acts of kindness? Might this sequencing help foster quiet acts of kindness? Further still, given their reliance to date on well-being interventions that have participants plan and do a series of kind acts, might researchers encourage a variety of kind acts as part of interventions?

\section{Conclusion}

This paper presented an overview of three categories of kindness performed by children-random acts of kindness where children spontaneously respond to others' needs, intentional acts where kindness is planned a priori, and quiet kindness, acts that quietly demonstrate a care and concern for others but in ways that largely go unnoticed by anyone but the initiator. It has been argued here that this latter version of kindness represents a more socially and emotionally sophisticated form of kindness and, resultingly, a kind of kindness that might fly beneath the radar of the reinforcing agents within children's learning communities. 


\section{References}

Aknin, L. B., Sandstrom, G. M., Dunn, E. W., \& Norton, M. I. (2011). It's the recipient that counts: Spending money on strong social ties leads to greater happiness than spending on weak social ties. PLOS ONE, 6, 1-3. https://doi.org/10.1371/journal.pone.0017018

Ashdown, D. M., \& Bernard, M. E. (2012). Can explicit instruction in social and emotional learning skills benefit the social-emotional development, well-being, and academic achievement of young children? Early Childhood Education Journal, 39, 397-405. doi:10.1007/s10643-011-0481-x

Biglan, A. (2003). Selection by consequences: One unifying principle for a transdisciplinary science of prevention. Prevention Science, 4, 213-232. doi:10.1023/A:1026064014562

Biglan, A., Flay, B. R., Embry, D. D., \& Sandler, I. N. (2012). The critical role of nurturing environments for promoting human well-being. American Psychologist, 67, 257-271. doi:10.1037/a0026796

Binfet, J. T. (2015). Not-so random acts of kindness: A guide to intentional kindness in the classroom. International Journal of Emotional Education, 7, 35-51. https://doaj.org/article/3706dae6f26b427caf8641d27d3f4983

Binfet, J. T. (2016). Kindness at school: What children's drawings reveal about themselves, their teachers, and their learning communities. Journal of Childhood Studies, 41, 29-42.

Binfet, J. T., \& Gaertner, A. (2015). Children's conceptualizations of kindness at school. Canadian Children, 40, 27-39. http://dx.doi. org/10.18357/jcs.v40i3.15167

Binfet, J. T., \& Passmore, H. A. (2017). The who, what, and where of school kindness: Exploring students' perspectives. Canadian Journal of School Psychology. Advance online publication. doi:10.1177/0829573517732202

Bower, A. A., \& Casas, J. F. (2016). What parents do when children are good: Parent reports of strategies for reinforcing early childhood prosocial behaviors. Journal of Child and Family Studies, 25, 1310-1324. doi:10.1007/s10826-015-0293-5.

Carlo, G., \& Randall, B. A. (2002). The development of a measure of prosocial behaviors for late adolescents. Journal of Youth and Adolescence, 31, 31-44. doi:10.1023/A:101403303

Chancellor, J., Margolis, S., Jacobs-Bao, K., \& Lyubomirsky, S. (2017). Everyday prosociality in the workplace: The reinforcing benefits of giving, getting, and glimpsing. Emotion. Advance online publication. doi:10.1037/emo0000321

Collaborative for Academic and Social and Emotional Learning. (2015). What is social and emotional learning? Retrieved from http:// www.casel.org/social-and-emotional-learning/

Cotney, J. L., \& Banerjee, R. (2017). Adolescents' conceptualizations of kindness and its links with well-being: A focus group study. Journal of Social and Personal Relationships. Advance online publication. https://doi.org/10.1177/0265407517738584

Curry, O. S., Rowland, L. A., Van Lissa, C., Zlotowitz, S., McAlaney, J., \& Whitehouse, H. (2018). Happy to help? A systematic review and meta-analysis of the effects of performing acts of kindness on the well-being of the actor. Journal of Experimental Social Psychology, 76, 320-329. doi:10.1016/j.jesp.2018.02.014

Dahl, A. (2015). The developing social context of infant helping in two U.S. samples. Child Development, 86, 1080-1093. doi:10.1111/ cdev.12361

Dahl, A., Satlof-Bedrick, E., Hammond, S., Drummond, J., Waugh, W., \& Brownell, C. (2017). Explicit scaffolding increases simple helping in younger infants. Developmental Psychology, 53, 407-416. doi:10.1037/dev0000244

Davidov, M., Vaish, A., Knafo-Noam, A., \& Hastings, P. D. (2016). The motivational foundations of prosocial behavior from a developmental perspective-evolutionary roots and key psychological mechanisms: Introduction to the special section. Child Development, 87, 1655-1667. doi:10.1111/cdev.12639

Dunn, E. W., Aknin, L. B., \& Norton, M. I. (2014). Prosocial spending and happiness: Using money to benefit others pays off. Current Directions in Psychological Science, 23, 41-47. doi:10.1177/0963721414525911 
Flannery, D. J., Vazsonyi, A. T., Liau, A. K., Guo, S., Powell, K. E., Atha, H., . . \& Embry, D. (2003). Initial behavior outcomes for the PeaceBuilders universal school-based violence prevention program. Developmental Psychology, 39, 292-308. doi:10.1037/00121649.39.2.292

Grusec, J. E., Goodnow, J. J., \& Kuczynski, L. (2000). New directions in analyses of parenting contributions to children's acquisition of values. Child Development, 71, 205-211. doi:10.1111/1467-8624.00135

Grusec, J. E., \& Redler, E. (1980). Attribution, reinforcement, and altruism: A developmental analysis. Developmental Psychology, 16, 525-534. doi:10.1037/0012-1649.16.5.525

Hardy, S. A., Carlo, G., \& Roesch, S. C. (2010). Links between adolescents' expected parental reactions and prosocial behavioral tendencies: The mediating role of prosocial values. Journal of Youth and Adolescence, 39, 84-95. doi:10.1007/s10964-008-9383-7

Hastings, P. D., Utendale, W. T., \& Sullivan, C. (2007). The socialization of prosocial development. In J. E. Grusec \& P. D. Hastings (Eds.), Handbook of socialization: Theory and research (pp. 638-664). New York, NY: Guilford. Retrieved from https://www. researchgate.net/publication/283998128_The_socialization_of_prosocial_development

Henderlong, J., \& Lepper, M. R. (2002). The effects of praise on children's intrinsic motivation: A review and synthesis. Psychological Bulletin, 128, 774-795. doi:10.1037//0033-2909.128.5.774

Herbert, A., \& Pavel, M. M. (1993). Random kindness and senseless acts of beauty. Volcano, CA: Volcano Press.

Howard, J. A., \& Barnett, M. A. (1981). Arousal of empathy and subsequent generosity in young children. The Journal of Genetic Psychology, 138, 307-308. doi:10.1080/00221325.1981.10534147

Jennings, P., \& Greenberg, M. (2009). The prosocial classroom: Teacher social and emotional competence in relation to student and classroom outcomes. Review of Educational Research, 79, 491-525.

Kalliopuska, M., \& Tiitinen, U. (1991). Influence of two developmental programmes on the empathy and prosociability of preschool children. Perceptual and Motor Skills, 72, 323-328. doi:10.2466/pms.1991.72.1.323

Kellam, S. G., Brown, C. H., Poduska, J. M., Ialongo, N. S., Wang, W., Toyinbo, P., . . \& Wilcox, H. C. (2008). Effects of a universal classroom behavior management program in first and second grades on young adult behavioral, psychiatric, and social outcomes. Drug and Alcohol Dependence, 95, S5-S28. doi:10.1016/j.drugalcdep.2008.01.004

Kerr, S. L., O’Donovan, A., \& Pepping, C. A. (2014). Can gratitude and kindness interventions enhance well-being in a clinical sample? Journal of Happiness Studies, 16, 17-36. doi:10.1007/s10902-013-9492-1

Layous, K., Nelson, K., Kurtz, J. L., \& Lyubomirsky, S. (2017). What triggers prosocial effort? A positive feedback loop between positive activities, kindness, and well-being. The Journal of Positive Psychology, 12, 385-398. doi:10.1080/17439760.2016.1198924

Layous, K., Nelson, K., Oberle, E., Schonert-Reichl, K., \& Lyubomirsky, S. (2012). Kindness counts: Prompting prosocial behavior in preadolescents boosts peer acceptance and well-being. PLOS ONE, 7, e51380.

O'Connell, B. H., O'Shea, D., \& Gallagher, S. (2015). Enhancing social relationships through positive psychology activities: A randomized controlled trial. The Journal of Positive Psychology, 11, 1-14. https://doi.org/10.1080/17439760.2015.1037860

Otake, K., Shimai, S., Tanaka-Matsumi, J., Otsui, K., \& Fredrickson, B. (2006). Happy people become happier through kindness: Counting kindness intervention. Journal of Happiness Studies, 7, 361-375.

Parke, R. D., \& Buriel, R. (2006). Socialization in the family: Ethnic and ecological perspectives. In W. Damon, R. M. Lerner, \& N. Eisenberg (Eds.), Handbook of child psychology, Vol. 3. Social, emotional, and personality development (6th ed.; pp. 429-504). Hoboken, NJ: Wiley.

Post, S. (2017). Rx: It's good to be good (G2BG) 2017 commentary: Prescribing volunteerism for health, happiness, resilience, and longevity. American Journal of Health Promotion, 31, 164-172.

Rimm-Kaufman, S. E., Pianta, R. C., \& Cox, M. J. (2000). Teachers' judgments of problems in the transition to kindergarten. Early 
Childhood Research Quarterly, 15, 147-166. doi:10.1016/S0885-2006(00)00049-1

Rowland, L. (2018). Kindness: Society's golden chain? The Psychologist, 31, 30-35. Retrieved from https://thepsychologist.bps.org.uk/ volume-2018/february-2018/kindness-societys-golden-chain

Rowland, L., \& Curry, O. S. (2018). A range of kindness activities boost happiness. The Journal of Social Psychology. Advance online publication. doi:101080/00224545.2018.1469461

Spivak, A. L., \& Farran, D. C. (2012). First-grade teacher behaviors and children's prosocial actions in classrooms. Early Education \& Development, 23, 623-639. doi:10.1080/10409289.2011.566164

Taylor, T. K., \& Biglan, A. (1998). Behavioral family interventions for improving child-rearing: A review of the literature for clinicians and policy makers. Clinical Child and Family Psychology Review, 1, 41-60. doi:10.1023/A:1021848315541

Trew, J. L., \& Alden, L. E. (2015). Kindness reduces avoidance goals in socially anxious individuals. Motivation \& Emotion, 39, $892-907$. doi:10.1007/s11031-015-9499-5

Warneken, F., \& Tomasello, M. (2014). Extrinsic rewards undermine altruistic tendencies in 20-month-olds. Motivation Science, 1, 43-48. http://dx.doi.org/10.1037/2333-8113.1.S.43

Warton, P. M., \& Goodnow, J. J. (1995). Money and children's household jobs: Parents' views of their interconnections. International Journal of Behavioral Development, 18, 335-350. doi:10.1177/016502549501800209 